Tạp chí Khoa học và Công nghệ biển T12 (2012). Số 2. Tr 47 - 63

\title{
THAY ĐỔI HÀM LƯợNG LIPÍT VÀ TỶ LỆ A XÍT BÉO TRONG CƠ, GAN VÀ TRÚNG CỦA CÁ CHẼM LATES CALCARIFER (BLOCH, 1790) THEO GIAI ĐOẠN THÀNH THỤC
}

\author{
PHẠM XUÂN KỲ, ĐÀO VIỆT HÀ, LÊ TRỌNG DŨNG, TRẦ MINH HUỆ
}

Viện Hải dương học

\begin{abstract}
Tóm tắt: Để làm sáng tỏ vai trò của lipit và một số a xít béo trong quá trình thành thục của cá chẽm cái Lates calcarifer tự nhiên, thay đổi hàm lương và tỷ lệ các thành phần này trong co, gan và trúng ở 5 giai đoạn buồng trứng (2-6) đã được khảo sát. Hệ số thành thuc (GSI) tăng đáng kể tù giai đoạn 2-5, giảm sau khi đẻ (giai đoạn 6). Hàm luợng lipit trong co giảm đáng kể, ngược với sụ gia tăng ở gan và trúng theo các giai đoạn thành thục. Thành phần các a xít béo được phát hiện khá phong phú trong các bộ phận của cá chẽm với sự uu thế của tỷ lệ (\% hàm luợng tổng số a xít béo) các a xít béo không no. Tỷ lệ các a xít nhu 16:0, 18:0, 18:1n-9, 20:4n-6 (AA), 20:5n-3 (EPA) và 22:6n-3 (DHA) trong các bộ phận có sư thay đổi theo các giai đoạn thành thục với các mức độ khác nhau. Ngoài ra, tổng tỷ lệ nhóm n-6 và $n-3$ cũng có sư thay đổi cùng với sư thay đổi của các tý lệ hàm luợng n-3/n-6, DHA/AA, DHA/EPA và EPA/AA trong suốt quá trình thành thuc. Các kết quả đạt được cho thấy rằng lipit đóng vai trò quan trọng trong quá trình sinh sản của cá chẽm. Các a xít nhu 16:0, 18:1n9, 22:5n-3, AA, EPA và DHA có sụ liên quan đến quá trình thành thuc, trong đó, DHA có thể là một thành phần cần thiết trong phát triển buồng trứng của loài cá này.
\end{abstract}

\section{GIỚI THIỆU}

Lipít và các a xít béo- thành phần chính của màng tế bào và các lipoprotein, có vai trò quan trọng trong nhiều chức năng sinh học như điều hòa phản ứng miễn dịch và sự thay đổi sinh lý hay tham gia vào quá trình sinh trưởng, thành thục và sinh sản ở động vật (Bell và cs, 1995). Lipít được tổng hợp và dự trữ trong mô có thể được vận chuyển đến các cơ quan khác nhau qua con đường lipoprotein. Ở cá, lipít- nguồn dự trữ năng lượng chính, được dùng làm năng lượng chuyển hóa trong thời kỳ di cư để đẻ nhưng phần lớn được sử dụng cho phát triển buồng trứng (Bell, 1998). Lipít và prôtít được vận chuyển đến tế bào trứng dưới dạng lipoprotein -vitellogenin (Wallace, 1985; Specker và Sullivan, 1994). Các a xít béo trong lipoprotein noãn hoàn, đặc biệt là các a xít không no mạch dài nhiều nối đôi (PUFA) đóng vai trò là chất dinh dưỡng trong nội chất (cytoplasm) của tế bào trứng- một nguồn dinh dưỡng dự trữ cho sự phát triển của phôi và là nguồn thức ăn 
cần thiết cho ấu trùng các loài cá (Watanabe, 1993; Furita và cs, 2000; Monroig và cs, 2009). Mặt khác chúng còn là tiền chất của prostaglandins, leukotrienes và thromboxanes trong chuyển hóa eicosanoid, ảnh hưởng đến quá trình phát triển phôi (Sargent, 1995; Bell và cs, 1997). Thêm vào đó, các a xít béo 1 nối đôi và PUFA là công cụ để nghiên cứu thành phần dinh dưỡng trong chuỗi thức ăn cần thiết cho sự phát triển trứng suốt quá trình thành thục sinh dục như ở loài cá Hypostomus affinis và Geophagus brasiliensis (Gomes và $\mathrm{cs}, 2009$ ). Thay đổi về hàm lượng lipít và một số a xít béo trong cơ, gan và tuyến sinh dục liên quan đến sự thành thục đã được tìm thấy ở các loài như cá chình Nhật bản Anguilla japonica (Ozaki và cs, 2008), cá tráp (white seabream) Diplodus sargus và (gilthead seabream) Sparus aurata (Pérez và cs, 2007), cá trê Nhật bản Silurus asotus (Shirai và cs, 2001), mummichog Fundulus heteroclitus (Jensen và Taylor, 2002), Perca fluviatilis (Blanchard và cs, 2005).

Cá chẽm Lates calcarifer, một loài cá sống rộng muối, có giá trị thương mại cao được nuôi ở một số nước châu Á, trong đó có Việt nam. Một số công trình nghiên cứu sinh hóa về cá chẽm như thành phần các a xít amin (Dayal và cs, 2003), thay đổi thành phần và hàm lượng a xít béo trong trứng và ấu trùng (Lục Minh Diệp và cs, 2009), thành phần a xít béo ở cơ cá tự nhiên (Ho và Paul, 2009), đánh giá chất lượng trứng qua lipít và các a xít béo (Nocillado và cs, 2000), khả năng chuyển hóa các a xít nhiều nối đôi có giá trị cao (highly unsaturated fatty a cid, HUFA) (Mohd-Yusof và cs, 2009) đã được quan tâm. Với nghiên cứu này, lần đầu tiên chúng tôi khảo sát hàm lượng lipít và các a xít béo trong cơ, gan và trứng với tình trạng thành thục của cá tự nhiên để cung cấp thêm số liệu cho việc tìm hiểu quá trình sinh lý sinh sản cũng như nhu cầu các a xít béo cần thiết cho sinh sản của loài cá này.

\section{MẪU VẬT VÀ PHƯƠNG PHÁP NGHIÊN CÚU}

\section{Mẫu cá}

Cá chẽm được đánh bắt ở đầm Nha Phu từ tháng 04-09/2010 bằng câu hoặc lưới. Cá được vận chuyển sống về phòng thí nghiệm. Sau khi cân trọng lượng cơ thể và đo chiều dài, buồng trứng được lấy ra để cân trọng lượng dùng cho việc tính hệ số thành thục sinh dục [GSI (\%) = trọng lượng buồng trứng/trọng lượng cơ thể bỏ nội tạng]. Một phần trứng được ngâm trong dung dịch formon $10 \%$ để làm tiêu bản xác định giai đoạn thành thục bằng phương pháp nhuộm Hematoxylin-Eosin. Phần lớn buồng trứng còn lại được giữ ở $30^{\circ}$ dùng để chiết tách lipít. Phần cơ và gan dùng cho phân tích lipít cũng được lưu giữ ở $30^{\circ} \mathrm{C}$. Số cá thể được dùng phân tích ở mỗi giai đoạn của buồng trứng là 3 cá cái, với trọng lượng từ 4,8-11,5 $\mathrm{kg}$ và chiều dài toàn thân từ $39-110 \mathrm{~cm}$. 


\section{Xác định các giai đoạn thành thục}

Buồng trứng được quan sát bằng mắt thường hoặc dưới kính hiển vi để xác định các đặc điểm cảm quang. Ngoài ra các tiêu bản buồng trứng $(10 \mu \mathrm{m})$ được nhuộm Hematoxyline- Eosin và quan sát dưới kính hiển vi có độ phóng đại 4 đến 100 lần. Các giai đọan phát triển của buồng trứng cá chẽm được phân chia dựa theo Kuldeep và Ajay, 1998.

\section{Tách chiết lipít và phân tích các a xít béo}

\subsection{Chiết lipít}

Lipít được tách chiết theo phương pháp của Bligh và Dyer (1959) với sự thay đổi nhỏ. 1-3 g mẫu của cơ, gan và trứng cá (mẫu tươi) sau khi làm nhuyễn được ngâm trong hỗn hợp dung môi chloroform : methanol : nước cất theo tỷ lệ $1: 2: 0,4$ trong 24 giờ. Mẫu được chiết lại với hỗn hợp dung môi trên từ 2-3 lần. Dịch chiết sau khi thu được lắc với chloroform và một thể tích nước nhất định, để phân lớp và thu lớp chloroform. Dịch chiết được cô chân không ở nhiệt độ $40-45^{\circ} \mathrm{C}$.

\subsection{Methylester}

Mẫu lipít được methylester theo phương pháp của Careau và Dubacg (1978).

\subsection{Phân tích các a xít béo}

Các a xít béo được phân tích trên máy sắc ký khí HP-6890 với cột mao quản có chiều dài $30 \mathrm{~m}$, độ dày film $0,25 \mu \mathrm{m}$, đường kính trong cột $0,32 \mathrm{~mm}$, đầu dò ion hóa bằng ngọn lửa (FID) $275^{\circ} \mathrm{C}$, chương trình nhiệt độ tối thiểu $180^{\circ} \mathrm{C}$, tối đa $240^{\circ} \mathrm{C}$, đầu vào (inlet) $220^{\circ} \mathrm{C}$, khí mang nitơ, thể tích mẫu tiêm $1 \mu$ l. Chất chuẩn sử dụng bao gồm các a xít béo palmitic (16:0), stearic (18:0), oleic (18:1n-9), linoleic (18:2n-6), arachidonic (20:4n-6), eicosapentaenoic (20:5n-3), và docosahexaenoic (22:6n-3). Hàm lượng của mỗi a xít béo được thể hiện bằng tỷ lệ \% trong tổng số hàm lượng các a xít béo.

\section{Xử lý số liệu}

Các giá trị dữ liệu được thể hiện ở dạng trung bình \pm sai số chuẩn (SE). Sự sai khác về hệ số thành thục, chỉ số gan/trọng lượng cơ thể, hàm lượng lipít và các a xít béo giữa các giai đoạn thành thục được xử lý bằng phân tích ANOVA một chiều với Tukey test. Sự khác biệt đáng kể được xem xét ở p<0,05.

\section{KẾT QUẢ VÀ THẢO LUẬN}

\section{Các giai đoạn thành thục của cá chẽm}

Có 5 giai đoạn được xác định gồm giai đoạn 2 (buồng trứng nghỉ), 3 (tái khởi phát 
thành thục), 4 (phát triển), 5 (chín và rụng trứng), 6 (sau khi đẻ) (hình 1).

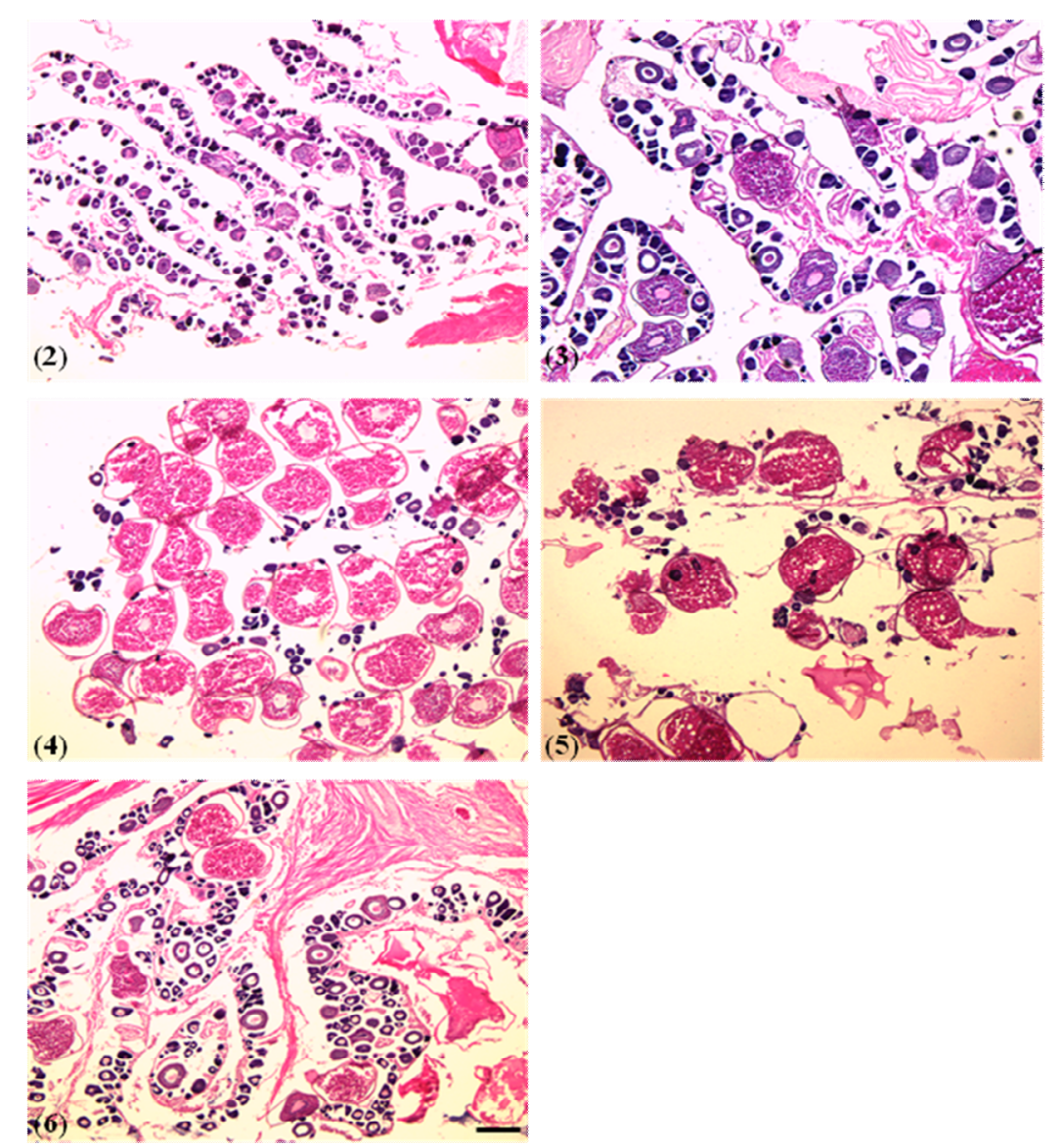

Hình 1: Các giai đoạn thành thục buồng trứng (2-6) cá chẽm Nha Phu, 2010, Thước chỉ thị $200 \mu \mathrm{m}$.

\section{Thay đổi hệ số thành thục sinh dục (GSI) và chỉ số trọng lượng gan/ buồng trứng} (HIS)

GSI tăng đáng kể suốt quá trình phát triển và thành thục của buồng trứng từ giai đoạn 2-5, giảm sau khi đẻ (giai đoạn 6) $(\mathrm{p}<0,05)$. Chỉ số HSI $(\%)$ không thay đổi đáng kể mặc dù nó có xu hướng cao ở giai đoạn 3 khi buồng trứng khởi phát quá trình thành thục (hình 2 ). 


\section{Hàm lượng lipít}

Hàm lượng lipít ( $\%$ trọng lượng tươii) trong cơ giảm đáng kể $(\mathrm{p}<0,05)$ từ giai đoạn 2- 6 từ 19,4 đến $0,43 \%$. Trong khi đó ở gan và buồng trứng, hàm lượng lipít tăng dần vào các giai đoạn 3-5 khi trứng phát triển, thành thục và giảm sau khi đẻ. Sự gia tăng lipít ở gan không lớn $(5,55-5,92 \%)$ nhưng ở buồng trứng là đáng kể $(2,66-4,68 \%, \mathrm{p}<0,05)$. Hàm lượng lipít trong cơ có xu hướng biến đổi ngược với hàm lượng lipít trong gan và trứng (hình 3).
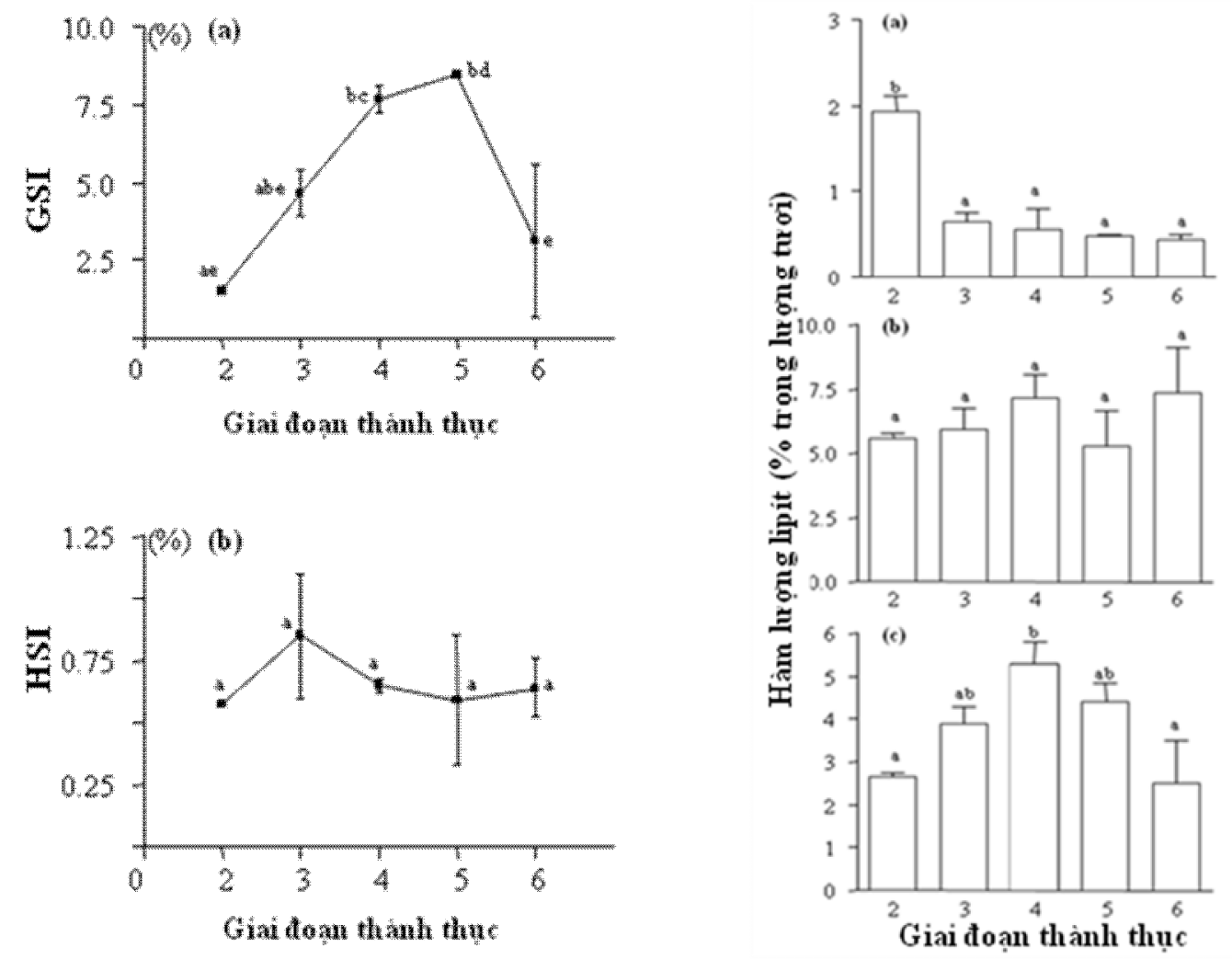

Hình 2: Thay đổi (a) GSI và (b) chỉ số HSI (\%) theo giai đoạn thành thục cá chẽm. Các ký tự khác nhau chỉ ra sự khác biệt đáng kể $(n=3, p<0,05)$.

Hình 3: Thay đổi hàm lượng lipít (\% trọng lượng tươi) trong (a) cơ, (b) gan và (c ) buồng trứng theo giai đoạn thành thục cá chẽm. Các ký tự khác nhau chỉ ra sự khác biệt đáng kể $(n=3, p<0,05)$.

\section{Thành phần và tỷ lệ các $a$ xít béo}

Tỷ lệ các a xít béo trong cơ, gan và buồng trứng ở các giai đoạn thành thục được 
trình bày trong các bảng $1-3$ và các hình 4,5 .

\section{Thành phần và tỷ lệ các a xít béo chủ yếu}

Thành phần và số lượng các a xít béo được phát hiện là như nhau ở các bộ phận được nghiên cứu. Trong đó, các a xít béo không no chiếm tỷ lệ lớn, đặc biệt là các a xít béo không no nhiều nối đôi. Trong các a xít no, 16:0 và 18:0 chiếm ưu thế với tỷ lệ cao của 16:0. Với các a xít béo 1 nối đôi, 18:1n-9 chiếm tỷ lệ lớn. Riêng ở buồng trứng, tỷ lệ các a xít $16: 1 \mathrm{n}-7$ và $18: 1 \mathrm{n}-7$ cũng tương đối lớn. Các a xít $18: 2$ n-6 và $D H A$ có tỷ lệ khá cao trong thành phần các a xít béo không no nhiều nối đôi trong các bộ phận ở các giai đoạn thành thục khác nhau. Các a xít không no khác như $\mathrm{AA}, \mathrm{EPA}$ và 22:5n-3 cũng có tỷ lệ đáng kể, đặc biệt trong buồng trứng.

\section{Thay đổi tỷ lệ các a xít béo theo giai đoạn thành thục}

Ở cơ, tổng tỷ lệ các a xít béo no tăng không đáng kể ở các giai đoạn thành thục nhưng các a xít chủ yếu như 16:0 tăng vào giai đoạn phát triển và rụng trứng (4-5), 18:0 ngược lại giảm đáng kể ở các giai đoạn này $(\mathrm{p}<0,05)$. Tổng tỷ lệ a xít 1 nối đôi có $x u$ hướng cao ở các giai đoạn trước khi sinh sản. Tỷ lệ 18:1n-9 giảm mạnh theo các giai đoạn thành thục $(\mathrm{p}<0,05)$. Trong các a xít không no nhiều nối đôi, tổng tỷ lệ nhóm n- 6 tăng nhẹ trong các giai đoạn từ 2-5 nhưng tỷ lệ $\mathrm{AA}$ không thay đổi đáng kể ở các giai đoạn thành thục ( $\mathrm{p}>0,05)$. Trong khi đó, tổng tỷ lệ nhóm n-3 giảm theo sự thành thục cùng với sự suy giảm đáng kể tỷ lệ DHA. Đồng thời, tỷ lệ hàm lượng nhóm n-3/n-6 cũng giảm trong thời kỳ này.

Ở gan, tổng tỷ lệ các a xít béo no có xu hướng tăng mạnh theo giai đoạn thành thục của buồng trứng cùng với sự tăng nhẹ của 16:0 và sự gia tăng đáng kể của 18:0 $(\mathrm{p}<0,05)$. Tổng tỷ lệ 1 nối đôi có xu hướng giảm theo thời kỳ thành thục đồng thời với sự giảm đáng kể tỷ lệ 18:1n-9 trong suốt thời kỳ này $(\mathrm{p}<0,05)$. Tổng tỷ lệ $\mathrm{n}-6$ với sự ưu thế của 18:2n-6 ít thay đổi nhưng AA thay đổi đáng kể qua các giai đoạn thành thục. Tổng tỷ lệ nhóm n-3 giảm nhẹ từ giai đoạn 2 đến 3 nhưng tăng nhẹ và ổn định ở các giai đoạn kế tiếp. Tỷ lệ của EPA và DHA giảm đáng kể từ giai đoạn 2 đến 3 nhưng tăng lên sau đó đến giai đoạn 5 khi trứng chín và thành thục $(\mathrm{p}<0,05)$. Tỷ lệ hàm lượng nhóm $\mathrm{n}-3 / \mathrm{n}-6$ giảm mạnh từ giai đoạn 2 đến 3 nhưng tăng ổn định ở các giai đoạn sau đó.

Ở buồng trứng, tổng tỷ lệ các a xít béo no giảm thấp vào giai đoạn $3(\mathrm{p}<0,05)$ và cao ở các giai đoạn còn lại. Tỷ lệ 16:0 giảm mạnh vào giai đoạn từ 2 đến $3(\mathrm{p}<0,05)$ trước khi tăng nhẹ vào các giai đoạn khác. Trong khi đó, tỷ lệ 18:0 ở các giai đoạn thành thục không có sự khác biệt đáng kể ( $\mathrm{p}>0,05)$. Tổng tỷ lệ 1 nối đôi cũng không khác nhau giữa các giai đoạn thành thục. Tổng tỷ lệ n-6 giảm mạnh vào thời kỳ chín và rụng trứng (giai đoạn 5 ) và thấp sau khi đẻ (giai đoạn 6) đồng thời với a xít 18:2n-6 (p<0,05). Tỷ lệ AA giảm đáng kể 
theo sự phát triển của buồng trứng $(\mathrm{p}<0,05)$. Trong khi đó, tổng tỷ lệ $\mathrm{n}-3$ cao vào thời kỳ trứng đang phát triển đến thành thục và rụng trứng (giai đoạn 3-5). Trong đó, tỷ lệ EPA tăng khá cao vào giai đoạn $4(\mathrm{p}<0,05)$ và cao sau khi đẻ (giai đoạn 6$)$; DHA tăng cao vào giai đoạn 5 khi trứng chín và rụng trứng. Tỷ lệ hàm lượng $n-3 / n-6$ tăng khá cao suốt thời kỳ thành thục của cá.

Bảng 1: Tỷ lệ (\%) các a xít béo trong cơ ở các giai đoạn thành thục cá chẽm thu ở Nha Phu 2010

\begin{tabular}{|c|c|c|c|c|c|c|c|c|c|c|}
\hline \multirow{3}{*}{$\begin{array}{l}\text { A xít } \\
14: 00\end{array}$} & \multicolumn{10}{|c|}{ Giai đoạn thành thục } \\
\hline & \multicolumn{2}{|r|}{2} & \multicolumn{2}{|r|}{3} & \multicolumn{2}{|c|}{4} & \multicolumn{2}{|r|}{5} & \multicolumn{2}{|c|}{6} \\
\hline & 1,6 & $\pm 0,14$ & 2,33 & $\pm 0,04$ & 2,89 & $\pm 0,09$ & 3,17 & $\pm 0,38$ & 1,72 & $\pm 0,2$ \\
\hline 16:00 & 20,82 & $\pm 0,9$ & 23,41 & $\pm 0,53$ & 23,64 & $\pm 0,3$ & 23,39 & $\pm 0,24$ & 21,78 & $\pm 0,54$ \\
\hline $18: 00$ & 10,86 & $\pm 0,49$ & 9,24 & $\pm 0,94$ & 8,23 & $\pm 0,12$ & 8,3 & $\pm 0,21$ & 9,61 & $\pm 0,47$ \\
\hline 20:00 & 0,19 & $\pm 0,04$ & 0,65 & $\pm 0,07$ & 0,57 & $\pm 0,06$ & 0,69 & $\pm 0,19$ & 0,55 & $\pm 0,09$ \\
\hline Tổng no & 33,46 & $\pm 0,52$ & 35,62 & $\pm 1,36$ & 35,33 & $\pm 0,28$ & 35,55 & $\pm 0,6$ & 33,67 & $\pm 0,93$ \\
\hline $16: 1 n-7$ & 5,57 & $\pm 0,33$ & 4,72 & $\pm 0,21$ & 7,52 & $\pm 0,62$ & 5,85 & $\pm 1,17$ & 5,51 & $\pm 1,69$ \\
\hline $18: 1 n-9$ & 17,92 & $\pm 0,67$ & 14,75 & $\pm 1,87$ & 16,91 & $\pm 1,03$ & 13,85 & $\pm 0,29$ & 12,29 & $\pm 0,97$ \\
\hline $18: 1 n-7$ & 4,24 & $\pm 0,09$ & 4,28 & $\pm 4,62$ & 1,97 & $\pm 0,78$ & 3,49 & $\pm 0,06$ & 2,01 & $\pm 0,68$ \\
\hline $20: 1 n-9$ & 0,57 & $\pm 0,06$ & 2,98 & $\pm 0,33$ & 2,44 & $\pm 0,29$ & 2,75 & $\pm 0,07$ & 1,44 & $\pm 0,28$ \\
\hline Tổng 1 nối đôi & 28,29 & $\pm 0,19$ & 26,73 & $\pm 2,21$ & 28,84 & $\pm 1,42$ & 25,93 & $\pm 1,02$ & 21,24 & $\pm 0,33$ \\
\hline $18: 2 n-6$ & 12,2 & $\pm 0,99$ & 13,11 & $\pm 0,11$ & 13,59 & $\pm 0,3$ & 12,3 & $\pm 0,02$ & 12,66 & $\pm 0,38$ \\
\hline $20: 4 n-6$ & 3,05 & $\pm 0,21$ & 2,75 & $\pm 0,21$ & 2,47 & $\pm 0,21$ & 2,41 & $\pm 0,38$ & 2,88 & $\pm 0,14$ \\
\hline $22: 4 n-6$ & 0,61 & $\pm 0,13$ & 1,4 & $\pm 0,22$ & 2,17 & $\pm 1,23$ & 1,62 & $\pm 0,6$ & 1,63 & $\pm 0,49$ \\
\hline Tổng n-6 & 15,85 & $\pm 1,06$ & 17,26 & $\pm 0,12$ & 18,24 & $\pm 0,82$ & 16,32 & \pm 1 & 17,17 & $\pm 0,41$ \\
\hline $18: 3 n-3$ & 0,49 & $\pm 0,08$ & 0,96 & $\pm 0,63$ & 1,36 & $\pm 0,13$ & 2,01 & $\pm 0,13$ & 1,67 & $\pm 0,6$ \\
\hline $20: 5 n-3$ & 3,36 & $\pm 0,11$ & 2,63 & $\pm 0,01$ & 1,74 & $\pm 0,15$ & 2,48 & $\pm 1,05$ & 2,72 & $\pm 0,9$ \\
\hline $22: 5 n-3$ & 2,25 & $\pm 0,21$ & 1,18 & $\pm 0,39$ & 1,22 & $\pm 0,45$ & 0,27 & $\pm 0,17$ & 1,26 & $\pm 0,1$ \\
\hline $22: 6 n-3$ & 15,07 & $\pm 0,19$ & 14,48 & $\pm 0,26$ & 12,04 & $\pm 1,82$ & 9,89 & $\pm 1,46$ & 14,72 & $\pm 0,75$ \\
\hline Tổng n-3 & 21,16 & $\pm 0,38$ & 19,23 & $\pm 0,49$ & 16,36 & $\pm 2,19$ & 14,65 & $\pm 0,45$ & 20,37 & $\pm 1,55$ \\
\hline Không xác định & 1,25 & $\pm 1,39$ & 1,18 & $\pm 0,47$ & 1,23 & $\pm 1,29$ & 7,56 & $\pm 3,08$ & 7,54 & $\pm 0,49$ \\
\hline DHA/AA & 4,94 & & 5,27 & & 4,87 & & 4,10 & & 5,11 & \\
\hline DHA/EPA & 4,49 & & 5,51 & & 6,92 & & 3,99 & & 5,41 & \\
\hline EPA/AA & 1,10 & & 0,96 & & $\overline{0,70}$ & & 1,03 & & 0,94 & \\
\hline$n-3 / n-6$ & 1,34 & & 1,11 & & 0,9 & & $\mathbf{0 , 9}$ & & 1,19 & \\
\hline
\end{tabular}


Bảng 2: Tỷ lệ (\%) các a xít béo trong gan ở các giai đoạn thành thục cá chẽm thu ở Nha Phu 2010

\begin{tabular}{|l|r|l|r|r|r|r|r|r|r|r|}
\hline A xít béo & \multicolumn{7}{|c|}{ Giai đoạn thành thục } \\
\hline & \multicolumn{2}{|c|}{$\mathbf{2}$} & \multicolumn{2}{|c|}{$\mathbf{3}$} & \multicolumn{2}{|c|}{$\mathbf{4}$} & \multicolumn{2}{|c|}{$\mathbf{5}$} & \multicolumn{2}{|c|}{} \\
\hline $14: 00$ & 0,59 & $\pm 0,04$ & 0,92 & $\pm 0,32$ & 1,15 & $\pm 0,43$ & 2,05 & $\pm 0,09$ & 0,94 & $\pm 0,1$ \\
\hline $16: 00$ & 19,85 & $\pm 0,96$ & 23,22 & $\pm 0,71$ & 21,29 & $\pm 0,32$ & 22,49 & $\pm 0,41$ & 21,08 & $\pm 0,13$ \\
\hline $18: 00$ & 6,67 & $\pm 0,19$ & 8,75 & $\pm 0,61$ & 8,68 & $\pm 0,49$ & 8,35 & $\pm 0,07$ & 10,11 & $\pm 0,65$ \\
\hline $20: 00$ & 1,9 & $\pm 0,14$ & 1,15 & $\pm 0,57$ & 1,17 & $\pm 0,51$ & 0,76 & $\pm 0,13$ & 1,8 & $\pm 0,7$ \\
\hline Tổng no & $\mathbf{2 9}$ & $\pm \mathbf{0 , 8 8}$ & $\mathbf{3 4 , 0 4}$ & $\pm \mathbf{1 , 1 1}$ & $\mathbf{3 2 , 2 9}$ & $\pm \mathbf{1 , 5 8}$ & $\mathbf{3 3 , 6 4}$ & $\pm \mathbf{0 , 3}$ & $\mathbf{3 3 , 9 4}$ & $\pm \mathbf{0 , 1 4}$ \\
\hline $16: 1 \mathrm{n}-7$ & 5,13 & $\pm 0,09$ & 4,95 & $\pm 0,05$ & 3,66 & $\pm 0,21$ & 3,68 & $\pm 0,25$ & 2,76 & $\pm 0,23$ \\
\hline $18: 1 \mathrm{n}-9$ & 20,88 & $\pm 0,63$ & 21,1 & $\pm 0,54$ & 20,1 & $\pm 0,28$ & 19,21 & $\pm 0,29$ & 18,89 & $\pm 0,12$ \\
\hline $18: 1 \mathrm{n}-7$ & 3,43 & $\pm 0,62$ & 3,38 & $\pm 0,34$ & 2,75 & $\pm 0,17$ & 2,42 & $\pm 0,54$ & 2,62 & $\pm 0,5$ \\
\hline $20: 1 \mathrm{n}-9$ & 0,86 & $\pm 0,18$ & 0,9 & $\pm 0,1$ & 0,7 & $\pm 0,16$ & 0,87 & $\pm 0,02$ & 0,51 & $\pm 0,15$ \\
\hline $\begin{array}{l}\text { Tổng 1 nối } \\
\text { đôi }\end{array}$ & $\mathbf{3 0 , 2 9}$ & $\pm \mathbf{0 , 9 8}$ & $\mathbf{3 0 , 3 3}$ & $\pm \mathbf{0 , 9 2}$ & $\mathbf{2 7 , 2 1}$ & $\pm \mathbf{0 , 4 4}$ & $\mathbf{2 6 , 1 7}$ & $\pm \mathbf{0 , 5 2}$ & $\mathbf{2 4 , 7 8}$ & $\pm \mathbf{0 , 7 2}$ \\
\hline $18: 2 \mathrm{n}-6$ & 14,26 & $\pm 0,66$ & 15,59 & $\pm 0,82$ & 14,01 & $\pm 0,31$ & 14,05 & $\pm 0,07$ & 14,44 & $\pm 0,27$ \\
\hline $20: 4 \mathrm{n}-6$ & 1,41 & $\pm 0,26$ & 1,22 & $\pm 0,04$ & 2,53 & $\pm 0,12$ & 2,31 & $\pm 0,23$ & 1,26 & $\pm 0,61$ \\
\hline $22: 4 \mathrm{n}-6$ & 0,4 & $\pm 0,07$ & 0,79 & $\pm 0,67$ & 1,09 & $\pm 0,57$ & 0,25 & $\pm 0,08$ & 1,13 & $\pm 0,49$ \\
\hline Tổng n-6 & $\mathbf{1 6 , 0 7}$ & $\pm \mathbf{0 , 8 6}$ & $\mathbf{1 7 , 5 9}$ & $\pm \mathbf{0 , 1 6}$ & $\mathbf{1 7 , 6 2}$ & $\pm \mathbf{0 , 9 5}$ & $\mathbf{1 6 , 6 1}$ & $\pm \mathbf{0 , 3 9}$ & $\mathbf{1 6 , 8 3}$ & $\pm \mathbf{0 , 9 7}$ \\
\hline $18: 3 \mathrm{n}-3$ & 2,12 & $\pm 0,25$ & 1,75 & $\pm 0,07$ & 1,23 & $\pm 0,33$ & 1,94 & $\pm 0,04$ & 2,03 & $\pm 0,81$ \\
\hline $20: 5 \mathrm{n}-3$ & 4,3 & $\pm 0,28$ & 1,56 & $\pm 0,06$ & 3,1 & $\pm 0,1$ & 3,55 & $\pm 0,07$ & 3,83 & $\pm 0,11$ \\
\hline $22: 5 \mathrm{n}-3$ & 2,23 & $\pm 0,04$ & 1,18 & $\pm 0,08$ & 1,18 & $\pm 0,11$ & 1,18 & $\pm 0,04$ & 1,9 & $\pm 0,5$ \\
\hline $22: 6 n-3$ & 7,92 & $\pm 0,25$ & 6,62 & $\pm 0,48$ & 8,65 & $\pm 0,12$ & 7,25 & $\pm 0,21$ & 6,54 & $\pm 0,17$ \\
\hline Tổng n-3 & $\mathbf{1 6 , 5 7}$ & $\pm \mathbf{0 , 8 3}$ & $\mathbf{1 1 , 1 1}$ & $\pm \mathbf{0 , 5 7}$ & $\mathbf{1 4 , 1 7}$ & $\pm \mathbf{0 , 5 7}$ & $\mathbf{1 3 , 9 2}$ & $\pm \mathbf{0 , 2 3}$ & $\mathbf{1 4 , 3}$ & $\pm \mathbf{0 , 9 7}$ \\
\hline $\begin{array}{l}\text { Không xác } \\
\text { định }\end{array}$ & 8,08 & $\pm 1,88$ & 6,93 & $\pm 1,34$ & 8,71 & $\pm 2,72$ & 9,67 & $\pm 0,21$ & 10,15 & $\pm 1,42$ \\
\hline DHA/AA & $\mathbf{5 , 6 2}$ & & $\mathbf{5 , 4 3}$ & & $\mathbf{3 , 4 2}$ & & $\mathbf{3 , 1 4}$ & & $\mathbf{5 , 1 9}$ & \\
\hline DHA/EPA & $\mathbf{1 , 8 4}$ & & $\mathbf{4 , 2 4}$ & & $\mathbf{2 , 7 9}$ & & $\mathbf{2 , 0 4}$ & & $\mathbf{1 , 7 1}$ & \\
\hline EPA/AA & $\mathbf{3 , 0 5}$ & & $\mathbf{1 , 2 8}$ & & $\mathbf{1 , 2 3}$ & & $\mathbf{1 , 5 4}$ & & $\mathbf{3 , 0 4}$ & \\
\hline n-3/n-6 & $\mathbf{1 , 0 3}$ & & $\mathbf{0 , 6 3}$ & & $\mathbf{0 , 8 1}$ & & $\mathbf{0 , 8 4}$ & & $\mathbf{0 , 8 5}$ & \\
\hline
\end{tabular}


Bảng 3: Tỷ lệ (\%) các a xít béo trong buồng trứng ở các giai đoạn thành thục cá chẽm thu ở Nha Phu 2010

\begin{tabular}{|c|c|c|c|c|c|c|c|c|c|c|}
\hline \multirow{3}{*}{\begin{tabular}{|l|} 
A xít béo \\
$14: 00$ \\
\end{tabular}} & \multicolumn{10}{|c|}{ Giai đoạn thành thục } \\
\hline & \multicolumn{2}{|c|}{2} & \multicolumn{2}{|c|}{3} & \multicolumn{2}{|c|}{4} & \multicolumn{2}{|r|}{5} & \multicolumn{2}{|c|}{6} \\
\hline & 1,2 & $\pm 0,14$ & 1,15 & $\pm 0,52$ & 1,4 & $\pm 0,1$ & 0,6 & $\pm 0,04$ & 0,75 & $\pm 0,22$ \\
\hline $16: 00$ & 25,12 & $\pm 0,05$ & 19,29 & $\pm 0,37$ & 21,81 & $\pm 0,9$ & 25,12 & $\pm 0,32$ & 21,54 & $\pm 0,14$ \\
\hline 18:00 & 7,44 & $\pm 0,13$ & 6,11 & $\pm 0,52$ & 7,14 & $\pm 1,01$ & 8,6 & $\pm 2,2$ & 9,11 & $\pm 0,27$ \\
\hline $20: 00$ & 0,26 & $\pm 0,04$ & 0,4 & $\pm 0,09$ & 0,48 & $\pm 0,04$ & 0,58 & $\pm 0,09$ & 0,49 & $\pm 0,23$ \\
\hline Tổng no & 34,01 & $\pm 0,29$ & 26,95 & $\pm 0,47$ & 30,83 & $\pm \mathbf{0 , 8 8}$ & 34,89 & $\pm 2,57$ & 31,88 & $\pm 0,33$ \\
\hline $16: 1 n-7$ & 3,49 & $\pm 0,08$ & 4,41 & $\pm 0,41$ & 3,27 & $\pm 0,21$ & 4,22 & $\pm 0,04$ & 3,16 & $\pm 0,01$ \\
\hline $18: 1 n-9$ & 6,06 & $\pm 0,03$ & 7,57 & $\pm 0,35$ & 8,53 & $\pm 0,4$ & 7,44 & $\pm 0,46$ & 6,78 & $\pm 0,14$ \\
\hline $18: 1 n-7$ & 4,84 & $\pm 0,51$ & 3,41 & $\pm 0,37$ & 3,83 & $\pm 0,08$ & 4,44 & $\pm 0,16$ & 3,51 & $\pm 0,34$ \\
\hline $\begin{array}{l}\text { Tổng } 1 \text { nối } \\
\text { đôi }\end{array}$ & 14,39 & $\pm 0,62$ & 15,38 & $\pm 0,98$ & 15,63 & $\pm 0,4$ & 16,09 & $\pm 0,33$ & 13,45 & $\pm 0,47$ \\
\hline $18: 2 n-6$ & 12,39 & $\pm 0,25$ & 12,31 & $\pm 0,12$ & 12,33 & $\pm 0,17$ & 8,27 & $\pm 0,08$ & 10,77 & $\pm 0,06$ \\
\hline $20: 4 n-6$ & 4,25 & $\pm 0,07$ & 3,71 & $\pm 0,1$ & 2,12 & $\pm 0,04$ & 1,15 & $\pm 0,07$ & 2,46 & $\pm 0,27$ \\
\hline $22: 4 n-6$ & 0,17 & $\pm 0,03$ & 0,46 & $\pm 0,41$ & 0,69 & $\pm 0,1$ & 0,33 & $\pm 0,06$ & 0,46 & $\pm 0,36$ \\
\hline Tổng n-6 & 16,81 & $\pm 0,35$ & 16,48 & $\pm 0,25$ & 15,14 & $\pm 0,23$ & 9,75 & $\pm 0,1$ & 13,68 & $\pm 0,16$ \\
\hline $18: 3 n-3$ & 1,59 & $\pm 0,04$ & 3,6 & $\pm 0,25$ & 2,87 & $\pm 0,85$ & 2,42 & $\pm 0,59$ & 1,44 & $\pm 0,08$ \\
\hline $20: 4 n-3$ & 2,22 & $\pm 0,3$ & 4,22 & $\pm 0,07$ & 3,84 & $\pm 0,06$ & 4 & $\pm 0,28$ & 3,15 & $\pm 0,07$ \\
\hline $20: 5 n-3$ & 4,66 & $\pm 0,08$ & 4,24 & $\pm 0,1$ & 3,36 & $\pm 0,21$ & 3,26 & $\pm 0,04$ & 2,76 & $\pm 0,32$ \\
\hline $22: 5 n-3$ & 3,34 & $\pm 0,08$ & 3,34 & $\pm 0,31$ & 5,58 & $\pm 0,37$ & 3,13 & $\pm 2,79$ & 4,16 & $\pm 1,98$ \\
\hline $22: 6 n-3$ & 22,64 & $\pm 0,71$ & 21,03 & $\pm 0,76$ & 22,21 & $\pm 0,16$ & 24,36 & $\pm 0,75$ & 19,64 & $\pm 0,73$ \\
\hline Tổng n-3 & 34,44 & $\pm 0,98$ & 36,44 & $\pm 0,79$ & 37,86 & $\pm 0,74$ & 37,16 & $\pm 2,96$ & 31,14 & $\pm 1,08$ \\
\hline $\begin{array}{l}\text { Không xác } \\
\text { định }\end{array}$ & 0,36 & $\pm 0,3$ & 4,76 & $\pm 0,52$ & 0,54 & $\pm 0,65$ & 2,12 & $\pm 0,04$ & 9,86 & $\pm 2,04$ \\
\hline DHA/AA & 5,33 & & 5,67 & & 10,48 & & 21,18 & & 7,98 & \\
\hline DHA/EPA & 4,86 & & 4,96 & & 6,61 & & $\mathbf{7 , 4 7}$ & & 7,12 & \\
\hline EPA/AA & 1,10 & & 1,14 & & 1,58 & & 2,83 & & 1,12 & \\
\hline$n-3 / n-6$ & 2,05 & & 2,21 & & 2,5 & & 3,81 & & 2,28 & \\
\hline
\end{tabular}




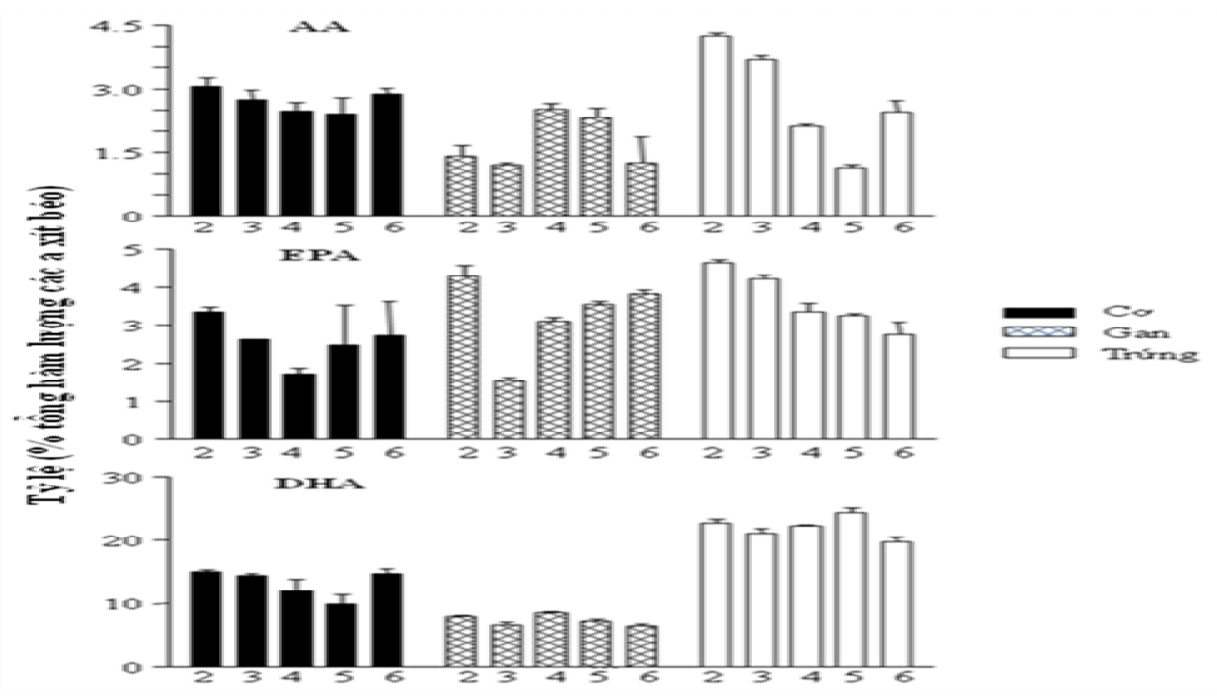

Giai đoạn thành thục

Hình 5: Thay đổi tỷ lệ $\mathrm{AA}$, EPA và DHA (\% tổng hàm lượngcác a xít béo) trong cơ, gan và buồng trứng theo giai đoạn thành thục cá chẽm. Các ký tự khác nhau chỉ ra sự khác biệt đáng kể $(n=3, p<0,05)$.

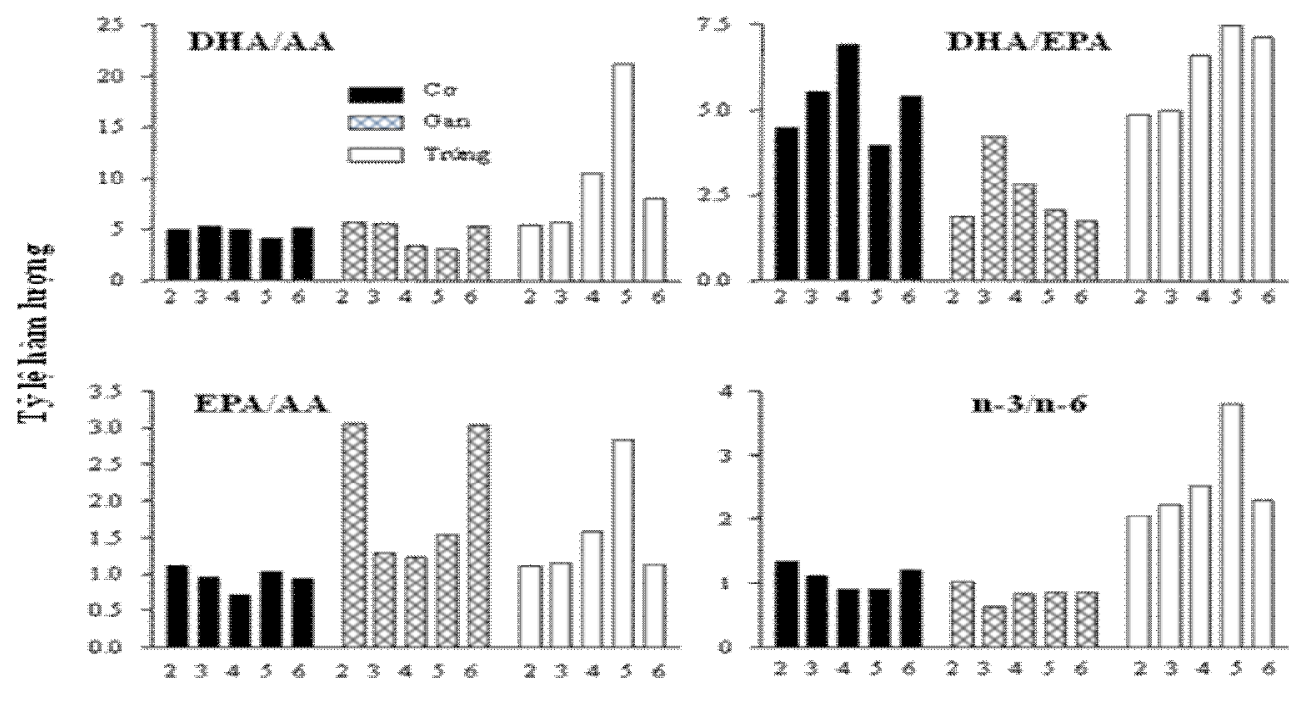

Giai đoạn thành thục

Hình 6: Thay đổi tỷ lệ hàm lượng DHA/AA, DHA/EPA, EPA/AA và n-3/n-6 trong cơ, gan và buồng trứng theo giai đoạn thành thục cá chẽm. 
Tỷ lệ các a xít 16:0 ở trứng cao nhưng 18:1n-9 thấp hơn cơ và gan. Trong các a xít không no nhiều nối đôi, tỷ lệ các a xít như 18:2n-6, AAvà EPA không có sự khác biệt lớn ở cơ, gan và trứng nhưng DHA ở trứng chiếm tỷ lệ khá cao, tiếp đến là cơ rồi gan. Tỷ lệ hàm lượng n-3/n-6 tăng theo gan, cơ, trứng (hình 6).

Tỷ lệ hàm lượng DHA/AA và DHA/EPA ở cơ thấp vào giai đoạn thành thục và rụng trứng (giai đoạn 5) so với các giai đoạn còn lại. Tỷ lệ hàm lượng DHA/AA cũng có xu hướng giảm theo giai đoạn thành thục ở gan và tỷ lệ hàm lượng DHA/EPA cao nhất ở giai đoạn 2. Các tỷ lệ này có chiều hướng gia tăng mạnh theo giai đoạn phát triển của buồng trứng. Trong khi đó, tỷ lệ hàm lượng EPA/AA ít thay đổi ở cơ, thấp ở gan và tăng cao ở buồng trứng vào các giai đoạn trứng phát triển và thành thục. Các tỷ lệ này ở trứng cao hơn cơ và gan (hình 6).

Sự thay đổi của hàm lượng lipít trong các bộ phận của cá chẽm trong quá trình thành thục và đẻ trứng cho thấy sự liên quan của nguồn vật chất này đến sinh sản. Sự suy giảm hàm lượng lipít trong cơ cùng với sự gia tăng của nó ở gan và trứng trong mùa sinh sản gợi ý rằng nguồn năng lượng và dỉnh dưỡng trong quá trình phát triển buồng trứng và các tổng hợp sinh học cho noãn hoàn được cung cấp từ cơ qua gan. Gan là cơ quan trung gian chuyển tiếp nguồn vật chất này (a xít béo) sang trứng. Nhìn chung, biến động hàm lượng lipít ở cá chẽm có xu hướng tương tự như một số loài cá biển khác như cá ngừ vây xanh Thunnus thynnus thynnus L (Mourente và cs, 2002), mummichog (Jensen và Taylor, 2002), capelin Mallotus villosus (Henderson và cs, 1984), lươn Nhật bản (Ozaki và cs, 2008)... nhưng mức độ thay đổi có khác nhau ở các bộ phận. Ở cá ngừ vây xanh và capelin- những loài cá khơi di cư đẻ xa, mức độ suy giảm lipít ở cơ và sự gia tăng ở buồng trứng trong quá trình sinh sản rất lớn vì ngoài việc cung cấp vật chất cho buồng trứng nó còn là nguồn năng lượng cho cơ bơi. Ví dụ, ở capelin, khoảng $40 \%$ lipít buồng trứng được cung cấp trực tiếp từ cơ qua gan. Trọng lượng gan gia tăng trước khi gia tăng trọng lượng buồng trứng và kích cỡ cũng như số lượng các giọt dầu trong gan tăng theo quá trình thành thục. Trong khi đó ở gan của mummichog hàm lượng lipít ít thay đổi. Ngược lại, ở giai đoạn đầu của sự phát triển buồng trứng của lươn Nhật bản, hàm lượng lipít trong cơ hầu như không đổi. Nguồn vật chất được sử dụng có thể là một nguồn khác như a xít amin. Đối với cá chẽm, chúng sống ở vùng nước gần bờ, di cư đi đẻ đến vùng nước lợ của sông, không trải qua quá trình di chuyển dài nên sự tiêu hao năng lượng ở cơ cho hoạt động bơi có thể thấp hơn các loài di cư đi đẻ xa khác. Xem xét những kết quả các nghiên cứu nêu trên và kết quả trong nghiên cứu này có thể nhận xét rằng sự biến đổi của hàm lượng lipít tuân theo quy luật từ cơ-gan-buồng trứng nhưng mức độ thay đổi khác nhau giữa các loài. Điều này có thể phụ thuộc tập tính dinh dưỡng, sinh sản và môi trường sống. Ở nhiều loài cá, hoạt động bắt mồi từ lúc tái khởi phát thành thục đến di cư giảm, có nghĩa 
là lipít được cung cấp từ nguồn thức ăn giảm. Tuy nhiên, suốt quá trình này kích thước và trọng lượng của buồng trứng vẫn tăng đáng kể. Kết quả này có thể do quá trình chuyển hóa các dòng vật chất và năng lượng khác nhau dự trữ xảy ra ở cá. Tuy nhiên, cũng như ở nhiều loài cá khác, sự chuyển hóa các dòng vật chất và năng lượng này là chưa rõ ở cá chẽm.

Thành phần các a xít béo được phát hiện trong các bộ phận của cá chẽm trong nghiên cứu này là khá phong phú, tương tự như thành phần các a xít trong cơ và trứng của loài này đã được công bố (Nocillado và cs, 2000; Ho và Paul, 2009). Ngoài ra tỷ lệ đáng kể của một số a xít thiết yếu không no mạch dài khác như $\mathrm{AA}, \mathrm{EPA}$ và $\mathrm{DHA}$ ở trứng là tương tự với kết quả của Lục Minh Diệp và cs, 2009. Cũng như các loài cá biển, ưu thế của các a xít không no như 18:1n-9, 18:2n-6, 22:5n-3, AA, EPA và DHA trong tất cả các mô được phân tích chứng tỏ sự cần thiết của chúng đối với sự phát triển tuyến sinh dục của loài nghiên cứu. Các nghiên cứu chỉ ra rằng, thành phần a xít béo phản ảnh nhu cầu $\mathrm{a}$ xít béo thiết yếu. Thành phần các $\mathrm{a}$ xít béo ở cá biển phần lớn phản ảnh thành phần này từ nguồn thức ăn, một phần khác do cơ thể tự tổng hợp. Sự thiếu hụt 22:1 trong phân tích này có lẽ do nguồn thức ăn. Giống như nhiều loài cá biển khác, cá chẽm không có khả năng tự tổng hợp các a xít không no mạch dài từ các a xít mạch ngắn (Mohd-Yusof và cs, 2009). Do đó việc cung cấp các a xít này từ nguồn thức ăn cho quá trình thành thục là quan trọng.

Nhiều a xít trong số được phát hiện có mối quan hệ với quá trình sinh sản của cá. Hàm lượng cao các a xít 16:0, 18:0 và 18:1n-9 trong mô cơ và gan chứng tỏ nguồn cung cấp năng lượng chủ yếu từ các a xít này. Một số nghiên cứu cho thấy trong quá trình hoạt động cần sự cung cấp năng lượng, việc sử dụng các a xít trên là chủ yếu, đặc biệt là 18:1n9. Ngoài ra chúng cũng tham gia vào các quá trình sinh học khác như tổng hợp các a xít béo mạch dài. Các a xít no và một nối đôi hấp thụ vào gan được tiêu thụ như là nguồn năng lượng cho tổng hợp sinh học lipoprotein. Trong khi đó, HUFA liên kết với phospholipids và triacylglycerols, tổng hợp lipít mới và qua aproprotein đặc trưng của trứng. Các lipoprotein này được vận chuyển đến trứng qua máu (Ozaki và cs, 2008). Ở cá chẽm, mặc dù tổng tỷ lệ các a xít no không thay đổi lớn qua các thời kỳ thành thục nhưng tỷ lệ các a xít 16:0 và 18:0 có sự biến động lớn. Điều này cho thấy các a xít này có một vai trò cần thiết trong quá trình thành thục và sinh sản của loài này.

Xu hướng biến động tỷ lệ các a xít no cũng như một số a xít không no quan trọng như DHA ở cá chẽm tương tự cá ngừ vây xanh. Ở cá hồi, tỷ lệ (\%) của DHA tăng cùng với sự phát triển trứng. Các a xít no và PUFA, đặc biệt nhóm n-3 như EPA và $\mathrm{DHA}$ cao ở trứng cá chẽm liên quan đến hàm lượng hóc môn estradiol (Phạm Xuân Kỳ và cs, 2010, tài liệu chưa công bố). Nghiên cứu ở 2 nhóm trứng thụ tinh và không thụ tinh cho thấy, ở cá chẽm, hàm lượng lipít, tổng số a xít no, EPA, DHA và nhóm n-3, n-6 cao ở nhóm trứng 
thụ tinh và hàm lượng tổng số a xít no có quan hệ thuận với tỷ lệ thụ tinh. Thêm vào đó, tổng số a xít no và $\mathrm{DHA}$ cũng có quan hệ thuận với sự phát triển phôi bình thường (Nocillado và cs, 2000). Trong nghiên cứu này, tổng tỷ lệ a xít no khá cao và $\mathrm{DHA}$ chiếm tỷ lệ lớn trong trứng so với cơ và gan, cũng như việc gia tăng hàm lượng a xít này trong quá trình thành thục có lẽ cũng liên quan đến việc đảm bảo sự thụ tinh và phát triển phôi và ấu trùng của cá chẽm tương tự như ở các loài cá mú châu Âu Dicentrarchus labrax (Sorbera và $\mathrm{cs}, 2001$ ), cá bơn Nhật bản (Furuita và cs, 2000), một số cá nước ngọt nhiệt đới như Piaractus mesopotamicus (Moreira và cs, 2003) và Pseudoplatystoma coruscans (Schreiner và cs, 2005). Ngoài ra, tổng tỷ lệ nhóm n-3 trong gan và trứng cao hơn cơ có thể hoặc các a xít này được sử dụng cho nhu cầu năng lượng ở cơ hoặc HUFA được tổng hợp ở gan và được chuyển sang trứng, giống như trường hợp của lươn Nhật bản (Ozaki và cs, 2008).

So sánh thành phần và tỷ lệ a xít béo ở cá nuôi và cá tự nhiên có thể giúp phỏng đoán nhu cầu a xít béo của loài. Mỗi giai đoạn phát triển có nhu cầu khác nhau về các $\mathrm{a}$ xít béo và tỷ lệ các a xít cũng có sự khác nhau theo loài. Chẳng hạn, ở cá ngừ vây xanh, tỷ lệ hàm lượng $\mathrm{DHA} / \mathrm{EPA} / \mathrm{AA}$ và $\mathrm{DHA} / \mathrm{EPA}$ lần lượt là 19,3/4,3/1 và 4,5/1 (Mourente và $\mathrm{cs}$, 2002). Việc thay đổi không thích hợp tỷ lệ hàm lượng $\mathrm{AA}$ và EPA/DHA trong khẩu phần ảnh hưởng đến hàm lượng gonadotropin $(\mathrm{GTH})$ và hóc môn steroid trong máu, làm suy giảm chất lượng và hoạt động đẻ của nhiều loài cá (Berndtson và cs, 1989; Knight và cs, 1995). Ở cá chẽm, hàm lượng đáng kể các a xít AA, EPA và DHA chứng tỏ tầm quan trọng của các loại này đối với sự thành thục sinh dục. Kết quả này cũng tương tự như các loài cá nhiệt đới khác được nghiên cứu (Emata và cs, 2003; Ogata và cs, 2004). Ngoài ra, tỷ lệ hàm lượng DHA/AA, DHA/EPA và EPA/AA thay đổi ở các bộ phận, đặc biệt ở buồng trứng trong quá trình sinh sản chứng tỏ nhu cầu cần thiết của các a xít này khác nhau theo từng giai đoạn thành thục. Đặc biệt, tỷ lệ DHA ở trứng tăng cao suốt thời kỳ thành thục và giảm đáng kể sau sinh sản gợi ý rằng nhu cầu DHA cho sự phát triển của buồng trứng cao hơn $\mathrm{EPA}$ và $\mathrm{AA}$ giống như ở cá bơn Scophthlmus minrus (Bell và cs, 1995), mặc dù sự cần thiết của $\mathrm{AA}$ và EPA cũng đáng được quan tâm. Các a xít này không được tổng hợp từ các a xít mạch ngắn ở cá chẽm (Mohd-Yusof và cs, 2009) và hàm lượng các a xít này ở trứng có thể bị ảnh hưởng bởi nguồn a xít béo trong thức ăn như lươn Nhật bản (Ozaki và cs, 2008), cá ngừ vây xanh (Mourente và cs, 2002), cá tráp gilthead seabream (Fernández-Palacios và cs, 1997). Mặt khác, sự thay đổi tỷ lệ hàm lượng n-3/n-6 ở các bộ phận, đặc biệt khá cao ở trứng, phản ảnh nhu cầu khác nhau của nhóm n-3 và n-6 của cá chẽm trong quá trình thành thục. Từ những kết quả trên, trong khẩu phần dinh dưỡng cần cung cấp nguồn các $a$ xít thiết yếu và tỷ lệ thích hợp n-3/n-6 để đảm bảo sự phát triển của buồng trứng cá chẽm. 


\section{KẾT LUẬN}

Các kết quả đạt được đã cho thấy rằng lipít và các a xít béo đóng vai trò quan trọng trong quá trình sinh sản của cá chẽm. Thành phần các xít béo khá phong phú ở các bộ phận của loài cá này với tỷ lệ khá lớn của các PUFA như 22:5n-3, AA, EPA và DHA, đặc biệt ở trứng. Các a xít như 16:0, 18:1n-9, 22:5n-3, AA, EPA và DHA ở cơ, gan và buồng trứng có sự liên quan đến quá trình thành thục của cá chẽm. Trong đó, DHA là một thành phần quan trọng trong phát triển buồng trứng loài cá này.

\section{TÀI LIỆU THAM KHẢO}

1. Bell JG, 1998. Current aspects of lipid nutrition in fish farming. In: Black K, Pickering AD (eds) Biology of farmed fish. Academic Press, Sheffield, pp 114-145.

2. Bell JG, Castell JD, Tocher DR, McDonaid FM and Sargent JR, 1995. Effects of different dietary arachidonic acid: docosahexaenoic acid ratios on phospholipid fatty acid composition and prostaglandin production in juvenile turbot (Scophthlmus minrus). Fish Physiol. Biochem. 14: 139-151.

3. Bell JG, Farndale BM, Bruce MP, Navas JM, Carillo M, 1997. Effects of broodstock dietary lipid on fatty acid compositions of eggs from sea bass, Dicentrarchus labrax. Aquaculture 149: 107-119.

4. Berndtson AK, Goetz FW and Duman P, 1989. In vitro ovulation, prostaglandin synthesis and proteolysis in isolated ovarian components of yellow perch (Perca

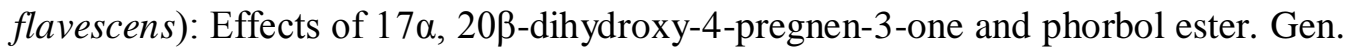
Comp. Endocrinol. 75: 454-465.

5. Blanchard G, Druart $X$ and Kestemont P, 2005. Lipid content and fatty acid composition of target tissues in wild Perca fluviatilis females in relation to hepatic status and gonad maturation. J. Fish Biol. 66: 73-85.

6. Bligh EG and Dyer WJ, 1959. A rapid methods of total lipid extraction and purification. Can. J. Biochem. Physiol. 37: 911-917.

7. Careau and Dubacg, 1978. Adaptation of a macro-scale method to the micro-scale for fatty acid methylesterification of biological lipid extracts. J. Chromatogr. 151: 384-390. 
8. Dayal SJ, Ahamad Ali S, Thirunavukkarasu AR, Kailasam M and Subburaj R, 2003. Nutrient and amino acid profiles of egg and larvae of Asian seabass, Lates calcarifer (Bloch). Fish Physiol. Biochem. 29: 141-147.

9. Emata AC, Ogata HY, Garibay ES and Furuita H, 2003. Advanced broodstock diets for the mangrove red snapper and a potential importance of arachidonic acid in eggs and fry. Fish Physiol. Biochem. 28: 489-491.

10. Furuita H, Tanaka H, Yamamoto T, Shiraishi $M$ and Takeuchi T, 2000. Effects of $n$-3 HUFA levels in broodstock diet on the reproductive performance and egg and larval quality of the Japanese flounder, Paralichthys olivaceus. Aquaculture 187: 387-398.

11. Gomes AD, Correia TG and Moreira RG, 2009. Fatty acids as trophic biomarkers in vitellogenic females in an impounded tropical river. Fish Physiol. Biochem. DOI 10,1007/s10695-009-9345-3.

12. Henderson RJ, Sargent JR and Hopkins CCE, 1984. Changes in the content and fatty acid composition of lipid in an isolated population of the capelin Mallotus villosus during sexual maturation and spawning. Mar. Biol. 78, 255-263.

13. Ho BT and Paul DR, 2009. Fatty acid profile of Tra Catfish (Pangasius hypophthalmus) compared to Atlantic Salmon (Salmo solar) and Asian Seabass (Lates calcarifer). Inter. Food Res J. 16: 501-506.

14. Jensen BH and Taylor MH, 2002. Lipid transport in female Fundulus heteroclitus during the reproductive season. Fish Physiol. Biochem. 25: 141-151.

15. Knight J, Holland JW, Bowden LA, Halliday K and Rowley AF, 1995. Eicosanoid generating capacities of different tissues from the rainbow trout (Oncorhynchus mykiss). Lipids 30:451-458.

16. Kuldeep KL and Ajay KP, 1998. Hypothalamo-neurosecretory system of the female sea bass, Lates calcarifer (Bloch), with special reference to gonadal maturation. Indian J. Fish. 45: 51-60.

17. Lục Minh Diệp, Nguyễn Hữu Dũng, Nguyễn Đình Mão, Luis ConceiCão, Maria Teresa Dinis, Elin Kjorsvik, Helge R.Reinertsen, 2009. Biến đổi thành phần và hàm lượng axít béo trong quá trình phát triển của trứng, ấu trứng cá Chẽm - Lates calcarifer (Bloch, 1790). Tạp chí Khoa học - Công nghệ Thủy sản, số 4. 
18. Mohd-Yusof NY, Monroig O, Mohd-Adnan A, Wan KL and Tocher DR, 2009. Investigation of highly unsaturated fatty acid metabolism in the Asian sea bass, Lates calcarifer. Fish Physiol. Biochem. DOI 10,1007/s10695-010-9409-4.

19. Monroig O, Rotllant J, Sanchez E, Cerda'-Reverter JM, Tocher DR, 2009. Expression patterns of genes of long-chain polyunsaturated fatty acid (LC-PUFA) biosynthesis during embryonic development of zebrafish Danio rerio. Biochim. Biophys. Acta. 1791:1093-1101.

20. Moreira RG, Zapata CRO, Bicudo JEPW, Parrish CC and Senhorini JA, 2003. Effects of broodstock diet on fatty acid composition of pacu Piaractus mesopotamicus eggs and larvae. In: Proceedings of World Aquaculture, Salvador, $p$ 500 .

21. Mourente G, C'esar Megina and $D^{\prime}$ 'raz-Salvago E, 2002. Lipids in female northern bluefin tuna (Thunnus thynnus thynnus L.) during sexual maturation. Fish Physiol. Biochem. 24: 351-363, 2002.

22. Nocillado JN, Peñaflorida VD and Borlongan IG. Measures of egg quality in induced spawns of the Asian sea bass, Lates calcarifer (Bloch) Fish Physio. Biochem. 22: 1-9.

23. Ogata HY, Emata AC, Garibay ES and Furuita H, 2004. Fatty acid composition of five candidate aquaculture species in Central Philippines Aquaculture 236: 361375.

24. Ozaki Y, Koga H, Takahashi T, Adachi S and Yamauchi K, 2008. Lipid content and fatty acid composition of muscle, liver, ovary and eggs of captive-reared and wild silver Japanese eel Anguilla japonica during artificial maturation. Fish. Sci. 74: 362-371.

25. Pérez MJ, Rodríguez C, Cejas JR, Martín MV, Jerez S and Lorenzo A, 2007. Lipid and fatty acid content in wild white seabream (Diplodus sargus) broodstock at different stages of the reproductive cycle. Comp. Biochem. Physiol. 146: 187-196.

26. Sargent JR, 1995. Ongins and functions of egg lipid: Nutritional implications. Brood stock management and egg and larval quality. Bromage NR. \& Roberts RJ (Eds). Blackwell Science Ltd University press, Cambridge, U.K.

27. Schreiner M, Andrade VXL, Moreira RG, Scorvo-Filho JD and Romagosa E, 2005. The influence of diet on the fatty acid composition of lipid storage tissues of surubim (Pseudoplatystoma coruscans) (Pisces: Teleostei) reared in cages. In: Proc 26th World Congress and Exhibition of the International Society for Fat Research. Praga, p 55. 
28. Shirai N, Suzuki H, Toukairin S and Wada S, 2001. Spawning and season affect lipid content and fatty acid composition of ovary and liver in Japanese catfish (Silurus asotus). Comp. Biochem. Physiol. 129: 185-95.

29. Sorbera LA, Asturiano JF, Carrillo M, and Zanuy S, 2001. Effects of Polyunsaturated Fatty Acids and Prostaglandins on Oocyte Maturation in a Marine Teleost, the European Sea Bass (Dicentrarchus labrax). Biol. Repro. 64: 382-389.

30. Specker JL and Sullivan CV, 1994. Vitellogenesis in fishes: status and perspectives. pp. 304- 315, in KG. Davey, RE. Peter and SS. Tobe, editors. Perspectives in Endocrinology, National Research Council, Ottawa, Canada.

31. Wallace RA and Selman K, 1985. Major protein changes during vitellogenesis and maturation of Fundulus oocytes. Dev. Biol. 110: 492-498.

32. Watanabe T., 1993. Importance of docosahexanoic acid in marine larval fish. J. Aquac. Society. 24: 153-161.

\title{
THE CHANGE OF LIPID CONTENT AND THE LEVEL OF FATTY ACIDS IN THE MUSCLE, LIVER AND OVARY OF THE SEA BASS LATES CALCARIFER (BLOCH, 1790) DURING OVARIAN MATURATION
}

\section{PHAM XUAN KY, DAO VIET HA, LE TRONG DUNG, TRAN MINH HUE}

\begin{abstract}
Summary: To elucidate the role of lipid and fatty acids in ovarian maturation in wild female Asian seabass Lates calcarifer, changes in their level in muscle, liver, and ovary in the five ovarian developmental stages (2-6) were investigated. The gonadosomatic index significantly increased from stages 2 to 5, and dropped after spawning (stage 6). Lipid content in muscle decreased significantly, contrary to liver and ovary where lipid content increased during ovarian maturation. Fatty acid composition was relatively abundant in the organs of the fish with the dominance of unsaturated fatty acids. Level (\% total fatty acids) of fatty acids 16:0, 18:0, 18:1n-9, 20:4n-6 (AA), 20:5n-3 (EPA) và 22:6n-3 (DHA) in these parts differently changed during ovarian maturation. In addition, the total level of $n-6$ and $n-3$ also changed together with the ratio of $n-3 / n-6, D H A / A A, D H A / E P A$, and EPA/AA during ovarian development. The results indicate that lipid plays an important role in reproduction of Asian seabass. Some fatty acids such as 16:0, 18:1n-9, 22:5n-3, AA, EPA, and DHA are involved in ovarian maturation, and DHA can be a necessary acid for ovarian maturation in this species.
\end{abstract} calcarifer

Keywords: fatty acid, AA, EPA, DHA, ovarian maturation, Asian seabass Lates Ngày nhận bài: 28 - 7 - 2011

Người nhận xét: TS. Nguyễn Thị Thanh Thủy 